\title{
Deceased donor liver transplantation from donors with central nervous system malignancy: Experience of the Inonu University
}

\author{
Volkan Ince, Veysel Ersan, Fatih Ozdemir, Bora Barut, Cemalettin Koc, Burak Isik, \\ Cuneyt Kayaalp, Sezai Yilmaz \\ Department of General Surgery, Inonu University, Liver Transplantation Institute, Malatya, Turkey
}

\begin{abstract}
OBJECTIVE: Liver transplantation from deceased donors with a central nervous system (CNS) malignancy has some risk of tumor transmission to the recipient. Though the risk is small, this group of donors is regarded as marginal. The use of marginal grafts may be an acceptable alternative practice in order to expand the donor pool in countries where there is a shortage of donated organs. The aim of this study was to examine and present the outcomes of liver transplantations performed using donors with a CNS tumor.

METHODS: Between March 2002 and July 2017, 1990 (deceased donor: $n=399,20 \%$; living donor: $n=1591$, $80 \%$ ) liver transplantations were performed at the center. Of the 399 deceased donors, 17 (4.2\%) had a CNS tumor. The data of donors with a CNS tumor and of recipients who survived for more than 1 month $(n=11)$ were retrospectively reviewed. Demographic data, the grade of the CNS tumor, tumor transmission to recipient data, and survival rates were analyzed.

RESULTS: Only 2 (18\%) grafts were provided locally, 6 (54\%) were offered to the transplantation center after all of the national centers had declined them, and 3 (37\%) were made available to us by the national coordination center for patients with a documented notification of urgency. High-grade (grade III-IV) brain tumors were detected in 7 (64\%) donors, while low-grade (grade I-II) tumors were found in 2 patients. The remaining 2 donors were not pathologically graded because the diagnosis was made radiologically. The 1-, 3-, and 5-year overall and tumor-free survival of the patients was estimated at $100 \%, 70 \%$, and $45 \%$, respectively.
\end{abstract}

CONCLUSION: A median survival of 40 months (range: 13-62 months) was achieved in recipients of grafts from a donor with a CNS tumor and no donor-related malignant transformation was observed.

Keywords: Central nervous system tumor; deceased; liver transplantation.

I $n$ countries where few organ donations are made, including ours, efforts to expand the donor pool continue. Transplantation centers may focus on living donor transplantation programs or may use non-optimal, marginal cadaver grafts. The Inonu
University Liver Transplantation Institute is the most widely used clinic in the country, and applies both of these solutions to perform more than 200 liver transplantations every year ( $80 \%$ from living donors [1-4].

Received: July 17, 2017 Accepted: August 07, 2017 Online: October 25, 2017

Correspondence: Dr. Volkan INCE. Inonu University Faculty Of Medicine, Department of General Surgery, Malatya, Turkey. Tel: +90 4223410660 e-mail: volkanince@outlook.com 
Cadaveric grafts harvested from donors with central nervous system (CNS) tumors are considered marginal grafts due to the risk of donor tumor cell migration and donor-derived tumor development in the recipient [5]. The World Health Organization classified primary brain tumors from grade I to grade IV based on biological behavior and prognosis. Grade IV tumors are cytologically malignant, usually fatal, and have the greatest risk of transmission from donor to recipient [6].

This study is an analysis of the results of liver transplantation using cadaveric donors with CNS tumors.

\section{MATERIALS AND METHODS}

The data of 1990 transplant patients who received a liver between March 2002 and July 2017 at the center from either living $(n=1591)$ or cadaveric $(n=399)$ donors were retrieved from a prospectively registered data bank. The data were retrospectively screened and 17 patients who received transplant livers from donors with a CNS tumor were identified. Since our objective was to determine whether any transmission of donor tumor cells to the recipients occurred, patients who were followed up for more than 1 month were included in the study. The demographic characteristics of the donors, the diagnostic method used for the CNS tumor, the type and histological stage of the tumor, the harvest and use of any other donor organs, the demographic characteristics of the transplant recipient, the length of survival, and the transmission of tumor cells from donor (if any) were recorded and assessed. KaplanMeier analysis was used to estimate survival of the transplant recipients.

\section{RESULTS}

The demographic characteristics of the donors with CNS tumors and of the recipients are presented in Tables 1 and 2, respectively. The diagnosis was established with histopathological analysis in 9 (82\%), and visualization of a mass in radiological images in $2(18 \%)$ of the donors. The donors had either grade III-IV ( $n=7,64 \%$; glioblastoma multiforme: $n=4$,
TABLE 1. Demographic data of the donors

\begin{tabular}{|c|c|}
\hline Parameters & $\mathrm{n}(\%)$ \\
\hline Age, median (years) (distribution range) & $34(3-71)$ \\
\hline \multicolumn{2}{|l|}{ Gender } \\
\hline Female & $7(64)$ \\
\hline Male & $4(36)$ \\
\hline \multicolumn{2}{|l|}{ Diagnosis } \\
\hline Histopathological examination & $8(91)$ \\
\hline Resection & 8 \\
\hline Biopsy & 1 \\
\hline Radiological & $2(9)$ \\
\hline \multicolumn{2}{|l|}{ Tumor histology } \\
\hline Glioblastoma multiforme & $4(36)$ \\
\hline Medulloblastoma & $2(18)$ \\
\hline Lymphoma (large B-cell) & $1(9)$ \\
\hline Schwannoma & $1(9)$ \\
\hline Neuroepithelial tumor & $1(9)$ \\
\hline \multicolumn{2}{|l|}{ Cerebral mass (radiological) } \\
\hline Porencephalic cystic/solid mass & $1(9)$ \\
\hline Choroid plexus papilloma & $1(9)$ \\
\hline \multicolumn{2}{|l|}{ Tumor grade } \\
\hline Low-grade (I-II) & $2(18)$ \\
\hline High-grade (III-IV) & $7(64)$ \\
\hline Radiological diagnosis & $2(18)$ \\
\hline \multicolumn{2}{|l|}{ Transplanted organs } \\
\hline Liver & $4(36)$ \\
\hline Liver+kidneys & $4(36)$ \\
\hline Liver+kidneys+cornea & $1(9)$ \\
\hline Liver+kidneys+heart+small bowel & $1(9)$ \\
\hline Liver+cornea & $1(9)$ \\
\hline \multicolumn{2}{|l|}{ Risk factors } \\
\hline \multicolumn{2}{|l|}{ Craniotomy } \\
\hline Yes & $9(82)$ \\
\hline No & $2(18)$ \\
\hline \multicolumn{2}{|l|}{ Ventriculoperitoneal shunt } \\
\hline Yes & $1(9)$ \\
\hline No & $5(45)$ \\
\hline Unknown & $5(45)$ \\
\hline \multicolumn{2}{|l|}{ History of chemotherapy or radiotherapy } \\
\hline Yes & $1(9)$ \\
\hline No & $9(82)$ \\
\hline Unknown & $1(9)$ \\
\hline
\end{tabular}

medullablastoma: $n=2$, lymphoma: $n=1$ ) or grade I-II ( $n=2,18 \%$; schwannoma: $n=1$, neuroepithelial tumor: $n=1)$ tumors. The 2 patients whose tumors were diagnosed based on radiological findings did 
not have histological grading. The liver, kidneys, heart, and small bowel of the 2 donors who had radiological diagnosis were used. The liver and cornea were transplanted from a donor with chronic renal failure who had been receiving hemodialysis. Only the liver was transplanted from 3 of the $7 \mathrm{pa}$ tients with a higher histopathological grade, while the liver and kidneys of the other 4 patients in that group were used. The liver was transplanted from 1 patient with a low-grade tumor, while the liver, kidneys, and cornea were transplanted from the other patient with a grade I-II tumor.

The median age of the transplant recipients was 32.9 years (range: $8-57$ years) and $6(54 \%)$ were male. The median Model for End-Stage Liver Disease/Pediatric End-Stage Liver Disease score was 17 (range: 7-30), and $46 \%$ were assessed as Child-Pugh classification C. In all, $91 \%(n=10)$ of the grafts were a complete liver graft, and 1 was a split graft used for 2 recipients. One of the patients who received the split liver transplantation died within the first month posttransplantation, and was therefore excluded from the study. Long-term mortality was observed in 6 of 11 patients who were followed up for a median 33 months (range: 13-62 months). The cause of death was sepsis in 4 cases and gastrointestinal bleeding in 1 . The remaining 5 patients were still living at the time of writing (median follow-up period:

\section{TABLE2. Demographic data of the recipients}

\begin{tabular}{|c|c|c|c|}
\hline \multicolumn{2}{|l|}{ Parameters } & \multicolumn{2}{|l|}{ Parameters } \\
\hline Age, median (years) (distribution range) & $32.9(8-57)$ & Organ source, $\mathrm{n}(\%)$ & \\
\hline Gender, n (\%) & & National (emergency) & $3(27)$ \\
\hline Female & $5(46)$ & National (not used by other centers) & $6(54)$ \\
\hline Male & $6(54)$ & Local (at our center) & $2(27)$ \\
\hline Child-Pugh class, n (\%) & & Mortality & \\
\hline A & $3(27)$ & Early (within the first 30 days) & $6(35)$ \\
\hline B & $3(27)$ & Cause of death ( $<30$ days), $n$ & \\
\hline $\begin{array}{l}\text { C } \\
\text { MFID/PFID score median (range) }\end{array}$ & $5(46)$ & Primary non-functional & 1 \\
\hline $\begin{array}{l}\text { MELD/PELD score, median (range) } \\
\text { Etiology, n (\%) }\end{array}$ & $17(7-30)$ & Postoperative bleeding & 1 \\
\hline Hepatitis B virus & $5(46)$ & Hepatic artery thrombosis & 1 \\
\hline Wilson disease & $1(9)$ & Sepsis & 3 \\
\hline Decompensated Wilson disease & $1(9)$ & Survival, days (months) & \\
\hline Alcohol consumption & $1(9)$ & Survived, n (tumor-free survival; & $5(46)$ \\
\hline Ecchinococcus alveolaris & $1(9)$ & median: 43 months; range: $14-60$ months & \\
\hline Primary sclerosing cholangitis & $1(9)$ & Died, n (tumor-free; median) & $6(54)$ \\
\hline Cholestatic liver disease & $1(9)$ & 33 months; range: $13-62$ months) & \\
\hline UNOS classification, n (\%) & & Cause of death ( $>30$ days) & \\
\hline 1 (intensive care unit patient) & $2(18)$ & Kaposi sarcoma & $1(9)$ \\
\hline 2 (inpatient) & $2(18)$ & Sepsis & $3(27)$ \\
\hline $\begin{array}{l}3 \text { (under medical treatment) } \\
4 \text { (at home; patients }\end{array}$ & $\begin{array}{l}5(46) \\
2(18)\end{array}$ & Acinetobacter & $1(9)$ \\
\hline with normal liver function) & & Influenza A virus & $1(9)$ \\
\hline Graft type, n (\%) & & Gastrointestinal bleeding & \\
\hline Full-size & $10(91)$ & Overall survival, months, median & $40(13-62)$ \\
\hline Segment 5-6-7-8 (split) & $1(9)$ & Disease-free survival, months, median & $40(13-62)$ \\
\hline
\end{tabular}

MELD: Model for End-Stage Liver Disease; PELD: Pediatric End-Stage Liver Disease; UNOS: United Network for Organ Sharing. 
43 months [range: 14-60 months]). The median length of follow-up of all patients was 40 months (range: 13-62 months), and during that time no donor-related malignancy was observed in any patient. The overall and tumor-free 1-, 3-, and 5-year survival rate was $100 \%, 70 \%$, and $45 \%$, respectively.

\section{DISCUSSION}

Among transplant donors, CNS tumor is the most frequently seen type of tumor after skin cancers. Since CNS tumors very rarely spread beyond the brain, there is some willingness to accept organs from these donors for transplant. While some literature data have scientifically proven the transmission of tumors cells from donors with CNS tumors to recipients [7], other reports have indicated only a small risk (or none) of transmission [8-11]. Therefore, the existing guidelines to be followed may be updated in the light of new data $[5,12-14]$.

In all of these guidelines, absolute contraindications for organ transplantation from donors with primary lymphoma of CNS and secondary intracranial malignancies are emphasized. In addition, whatever the tumor type, it is stressed that preexisting craniotomy, ventriculoperitoneal shunt, or history of chemotherapy/radiotherapy increases the risk of transmission of tumor cells. Based on UK data, the overall risk is $1.5 \%$, and increases to $2.2 \%$ in grade IV CNS tumors. It has been accepted that a ventriculoperitoneal shunt increases the risk of extracranial metastases at an estimated rate of less than 1\% [13]. In our study, despite the prevalence of unfavorable criteria, such as high-grade CNS tumors (64\%) and craniotomy (82\%), transmission of donor-related tumor cells was not detected in any transplant recipient. Furthermore, transmission of tumor cells was not detected in a recipient of a liver from a donor with CNS lymphoma, which is generally considered an absolute contraindication [15]. Similarly, other studies with a large database reported no transmission of tumor cells from donors with high-grade CNS tumors to transplant recipients [9-11].

Therefore, in our country, where the procurement of transplant organs is an issue, these donated organs with a very low risk of transmission of tumor cells should not be discarded. The patients who could benefit from their transplantation should be taken into consideration, and each case should be evaluated individually. Detailed informed consent was obtained from all of our patients to use these organs.

In our study, the transplant of organs of 11 donors with CNS tumors was analyzed. In all, the organs of 9 donors with a histopathological diagnosis (the liver of 4 patients, and the liver and kidneys of 5 patients) and 2 donors with a radiological diagnosis (the liver and corneas of 1 patient with chronic renal failure, and the liver, kidneys, heart, and small bowel of the other patient) were used. Though there is some hesitancy concerning the use of these organs, successful transplantation can be performed. Six (54\%) of these organs were made available by the national coordination center to organ transplantation centers but were rejected before being offered to us. Two of these 6 patients exited (at 26 and 62 months), while 4 are still living (range: $14-48$ months since transplantation). If we had not used these organs they would have been discarded.

Early phase mortality was observed in 6 of 17 cases ( primary nonfunctional kidney $\div \mathrm{n}=1$, bleeding $* \mathrm{n}=1$ ). Long-term mortality was seen in 6 patients, most frequently related to sepsis $(n=4)$. The other causes of long-term mortality were Kaposi sarcoma $(n=1)$ and gastrointestinal bleeding $(n=1)$. The median follow-up of the patients who died in the long-term was 33 months (rangeः 13-62 months), and all found to be were tumor-free.

In conclusion, including marginal donors with CNS tumors expanded our organ pool by $4.2 \%$ (17/399). We achieved a median survival of 40 months (range: 13-62 months) with these grafts, and no transmission of donor-related malignancy was observed in any recipient.

Conflict of Interest: No conflict of interest was declared by the authors.

Financial Disclosure: The authors declared that this study has received no financial support.

Authorship contributions: Concept - V.I.; Design - V.E.; Supervision - B.I.; Materials - F.O., C.K.,; Data collection \&/or processing - B.B, C.K.; Analysis and/or interpretation - C.K.; Writing - V.I., V.E.; Critical review - S.Y. 


\section{REFERENCES}

1. Kayaalp C, Ince V, Ersan V, Karakas S, Kahraman AS, Yilmaz S. Liver Transplantation for Hepatocellular Carcinoma at Inonu University. J Gastrointest Cancer 2017. [CrossRef]

2. Soyer V, Koc S, Onur A, Sarıc1 B, Kayaalp C, Isık B, et al. Futility Versus Acceptability of the Use of Grafts Taken From End of Line in the National Organ-Sharing Network. Transplant Proc 2015;47:1257-61. [CrossRef]

3. Tolan K, Kayaalp C, Ispir M, Kirmizi S, Yilmaz S. Having a Healthy Birth With a 100-Year-Old Liver. Prog Transplant 2016;26:392-3. [CrossRef]

4. Dirican A, Soyer V, Koc S, Yagci MA, Sarici B, Onur A, et al. Liver Transplantation With Livers From Octogenarians and a Nonagenarian. Transplant Proc 2015;47:1323-5. [CrossRef]

5. The Transplantation Society of Australia and New Zeeland. Clinical Guidelines for Organ Transplantation from Deceased Donors 2017. Available at: http://www.tsanz.com.au/organallocationguidelines/documents/ClinicalGuidelinesV1.1May2017. pdf. Accessed Oct 25, 2017.

6. Louis DN, Ohgaki H, Wiestler OD, Cavenee WK, Burger PC, Jouvet A, et al. The 2007 WHO classification of tumours of the central nervous system. Acta Neuropathol 2007;114:97-109.

7. Zhao P, Strohl A, Gonzalez C, Fishbein T, Rosen-Bronson S, Kallakury B, et al. Donor transmission of pineoblastoma in a two-yr-old male recipient of a multivisceral transplant: a case report. Pediatr Transplant 2012;16:110-4. [CrossRef]

8. Kauffman HM, Cherikh WS, McBride MA, Cheng Y, Hanto DW. Deceased donors with a past history of malignancy: an organ procurement and transplantation network/united network for organ sharing update. Transplantation 2007;27;84:272-4.
9. Watson CJ, Roberts R, Wright KA, Greenberg DC, Rous BA, Brown $\mathrm{CH}$, et al. How safe is it to transplant organs from deceased donors with primary intracranial malignancy? An analysis of UK Registry data. Am J Transplant 2010;10:1437-44.

10. Pokorna, E and Vitko S. The fate of recipients of organs from donors with diagnosis of primary brain tumor. Transpl Int 2001;14:346-7. [CrossRef]

11. Chui AK, Herbertt K, Wang LS, Kyd G, Hodgeman G, Verran DJ, et al. Risk of tumor transmission in transplantation from donors with primary brain tumors: an Australian and New Zealand registry report. Transplant Proc 1999;31:1266-7. [CrossRef]

12. European Directorate for the Quality of Medicines \& HealthCare of the Council of Europe. Guide to the quality and safety of organs for transplantation. 6th ed. Council of Europe; 2016.

13. Advisory Committee on the Safety of Blood, Tissues and Organs. Transplanation of Organs From Deceased Donors With Cancer or a History of Cancer 2014. Available at: https://www. gov.uk/government/uploads/system/uploads/attachment_ data/file/304261/Transplantation_of_organs_from_deceased_ donors_with_cancer_or_a_history_of_cancer.pdf. Accessed Oct 25, 2017.

14. Nalesnik MA, Woodle ES, Dimaio JM, Vasudev B, Teperman LW, Covington $\mathrm{S}$, et al. Donor-transmitted malignancies in organ transplantation: assessment of clinical risk. Am J Transplant 2011;11:1140-7. [CrossRef]

15. Isik B, Yilmaz S, Kirimlioglu V, Kirimlioglu H, Yilmaz M, Sogutlu G, et al. Kaposi's sarcoma after liver transplantation from a donor with a history of ventriculoperitoneal shunt and craniotomy for primary central nervous system lymphoma: report of a case. Surg Today 2008;38:90-4. [CrossRef] 